\title{
INFLUENCE OF POWER ASYMMETRY, COMMITMENT AND TRUST ON SME RETAILERS' PERFORMANCE
}

\author{
Anton SETYAWAN ${ }^{1}$, Ihwan SUSILA ${ }^{2}$, Sekar ANINDITA ${ }^{3}$ \\ Universitas Muhammadiyah Surakarta, Sukoharjo, Indonesia \\ E-mails: ${ }^{1}$ anton.setyawan@ums.ac.id (corresponding author); \\ 2ihwan.susila@ums.ac.id; ${ }^{3}$ sekarmirahh@gmail.com
}

Received 13 February 2019; accepted 26 March 2019

\begin{abstract}
The purpose of this study is to analyze the effect of power asymmetry, commitment and trust to business performance. In a business relation, the role of power asymmetry, commitment and trust are importance to maintain the quality of a relationship. Business performance is an important factor to decide whether a business relation should be continued or terminated. We conducted a survey with traditional SME retailers in Indonesia as the respondents, which were obtained through purposive sampling methods. This study involved 245 SME retailers who have business relation with modern companies as their supplier. We adopted Morgan and Hunt's (1994) model of relationship marketing for business to business in order to analyze the relationship among companies in business network. The result shows that power asymmetry, commitment and trust have significant, positive effects on business performance. The implication of this study is: power asymmetry between modern companies and SME potentially accelerates their performance, while commitment and trust will provide firm foundation for the companies involved in the business relation. In overall, power asymmetry has impact for firm with lack of bargaining position in business relation, thus instead of being exploited, SME retailers can increase their business performance due to partner's pressure and demand to their performance.
\end{abstract}

Keywords: power asymmetry, commitment, trust, business performance.

JEL Classification: M31, L16.

\section{Introduction}

Relationships between large companies and SMEs become critical issue among business partnerships in Indonesia. Such a partnership is a vital element to encourage the improvement in SME business performance. Meanwhile, studies of business relation among companies in the field of marketing management basically employ a relationship marketing framework (Morgan and Hunt 1994, Gronroos 1994, Viitaharju and Lahdesmaki 2012). In fact, relationship between companies survives as long as both parties gain benefit from it, certainly by taking into account the costs required for such a relationship (Ramaseshan et al. 2006).

Maloni and Benton (2000) claim that in a business relation, each party has certain power which brings positive and negative implications. The positive aspect is that it can enhance the business performance of both parties to meet the quality standards set by the business partnership. The negative aspect is exploitation by one party that has dominant power over the partner.

Briefly, the power in a business relation is often unequal. This condition is referred to as power asymmetry (Hingley 2005). Nevertheless, the role of power in a business relation has been examined in several empirical studies. Butaney and Wortzel (1988) investigated the role of power in relational association between two parties. It identified the characteristics of the customer market power and manufacturer market power that influence the demand of members of the distribution channel and their ability to use certain power. The role of power in inter-firm business relation, on several dependent variables, is mediated or moderated by other variables. Kim (2000) examined several moderating

Copyright @ 2019 The Authors. Published by VGTU Press.

This is an Open Access article distributed under the terms of the Creative Commons Attribution License (http://creativecommons.org/licenses/by/4.0/), which permits unrestricted use, distribution, and reproduction in any medium, provided the original author and source are credited.. 
variables that link the power asymmetry with the strategy used by the firm.

Morgan and Hunt (1994) emphasize the importance of variables of commitment and trust, which are then referred to as moderating variables for the relationship between power asymmetry and business performance. Based on empirical theory and research, the power asymmetry has an impact on the commitment of each party in a relationship (Srinivasan and Moorman 2005, Fullerton 2005). The wider the power asymmetry, which indicates the occurrence of exploitative relationship, the increasingly lower the commitment of the aggrieved party.

Spekman and Carraway (2006) and Gronroos (1994) argue that the basic component of business relations is trust. Moreover, Deutsch in Lau and Lee (2000) suggests trust as the expectation of the parties in a transaction and the risks associated with estimation and behaviour towards those expectations. Lau and Lee (2000) also states that shortly, trust is an expression of feeling.

The present study investigates the relationship between power asymmetry, trust and commitment in business relations in the Indonesian retail industry. The theoretical framework developed by Morgan and Hunt (1994) and Ramaseshan et al. (2006) was employed. Based on this theoretical framework, power asymmetry, commitment and trust are the explanatory variables for the business performance of SME retailers who have business relations with large companies. This study uses a survey approach, by involving $245 \mathrm{SME}$ retailers as respondents.

\section{Theoretical frameworks}

\subsection{Power assymetry and business performance}

Power is source of bargaining position of organization against their partners (Kim 2000, Ramseshan et al. 2006). It is the capability to influence other (Ramaseshan et al. 2006). Organizations have diverse sources of power. Ratnasingam (2000) classifies the power of an organization based on the sources of power, namely: (1) non-coercive power: the power of an organization as the result of appreciation, expertise, recommendations and legitimation, and (2) coercive power: the derivation of an organization's ability to impose sanction and penalty on its partner/s. Butaney and Wortzel (1988) identify the characteristics of the power of customer or manufacturer is similar to the power of the distribution channel. Power can be derived from the level of satisfaction to channel the achievements and relative resources of distributor channel.

Essentially, two parties connected in business relations have interdependent association. Total interdependence is the sum of firms' dependence, while asymmetric interdependence is the difference between a firm's dependence on its partners and the partner's dependence on the firm
(Emerson 1962, Lawler and Bacharach 1987 in Buuren (2017). Such a difference is also referred to as the more or less dependent partner's relative power (Buuren 2017). Furthermore, symmetrical interdependence occurs when firm and partner are evenly dependent on each other since the firm's dependence on a partner is a source of power for that partner (Emerson 1962) in Buuren (2017). Total interdependence and asymmetric interdependence are comparable to the total power and asymmetry power derived from the firms' dependence (Kumar and Al 1995 in Buuren 2017).

Furthermore, in the context of the influence strategy of producers and retailers, Porter (1980) argues that producers dominate their influence strategy towards retailers in the market structure of oligopoly, and have regulated switching costs and customer products are important parts of the final product or production process. Meanwhile, the costumer industry dominates the influence strategies in business relations when buying numbers of products, and these products have both low switching costs and transparent market information.

In the context of business relations between two parties, there are specific situations when one party has a higher power, for instance in the partnership between modern retailer and SME under the relationship of retail-supplier. In such a situation, there is a possibility that the relations become more intense and powerful, yet there is an imbalance of power between them. It will be detrimental for the existing business relations. Eventually, the resulted power asymmetry will construct the quality of the business relationship among partners that is possibly worsened and might lead to the firm's declining performance.

H1 - Power asymmetry influences the performance of SME retailers.

\subsection{Trust, commitment and effect on business performance}

Trust is defined as the expectation that the other party will project as expected and treat it fairly and reasonably (Suvanto 2012). In this case, trust is divided into two aspects, namely cognitive and affective aspect. On the cognitive aspect, it refers to the actor's perceptions that the expected performance has been performed (Suvanto 2012). Meanwhile, affective aspects explain the intrinsic values that are ascribed to actors, and attention as indicated by interactions (Ryu et al. 2008). In organizational relations, trust is identified as a component of management relations that is deemed "weak" due to its possibility to trigger conflicts between two parties. As a consequence, there are many elements that have impact on trust and eventually influence the performance and relationship between actors from diverse organizations (Ryu et al. 2008).

Trust is a vital aspect in organizational networks. These organizations are likely to maintain a trusting relationship 
among them in various partnerships in order to determine effective and efficient strategies to achieving success and optimizing their performances. Trust is a critical predictor of behaviour in organizations (Ryu et al. 2008). Intensification of trust leads to concern for their own relationships and the emphasis in building and maintaining further relationships to develop the performance and satisfaction of organizational members (Maloni and Benton 2000). Strong relationships are built on trust, allowing the involving parties to optimize synergy and respond quickly to resolving problems among them.

In the present study, trust between retailer and supplier becomes a necessity to continue a business relation. The supplier's trust is a guarantee that the partner is reliable and both of them have integrity (Rufin and Molina 2015). In this context, trust is defined as the contributor and facilitator for every single transaction that requires participation and cooperation of all parties (Suvanto 2012).

Sahadev (2008) claims that trust between suppliers and retail companies has been perceived as a significant predictor that influences the supplier's capacity to integrate supply chain activities. Meanwhile, Vesna and Brencic (2004) argue that trust plays an important role in enabling and enhancing the firm's innovation, and consequently influencing the supply chain performance. In fact, the integration of SMEs into the supply chain is a must. Hence, the suppliers' trust should be understood appropriately to build a rigid integration and optimize their performance.

H2 - Trust on partner influences the performance of SME retailers.

Commitment plays an important role in the relations among firms. It refers to the trust among partners in carrying out a continuous relationship, which is very crucial to ensure optimum effort in maintaining it. The two committed parties must believe that the relationship will last very long (Kwon and Suh 2005). Commitment between trading partners refers to the willingness of retailers and suppliers to conduct business in the name of the relationship (Wu et al. 2004). It is a fundamental variable for long-term success since partners in the supply chain have the willingness to invest their resources as well as provide short-term benefits for long-term success. Organizations establish and sustain long-term relationships if both parties experience mutually beneficial results obtained from that commitment.

Commitment, whether in inter-organizational, intraorganizational and interpersonal relationships, requires stability and sacrifice (Wu et al. 2004). It implies that all members are willing to make short-term requirements to maintain long-term and steady relationships. Wu et al. (2004) suggest commitment as a multifaceted construct and must be perceived from three aspects, namely:

1. Affective commitment

2. Normative commitment

3. Continuous commitment
In general, affective commitment refers to the sense of belonging and attachment to the organization, continuous commitment is related to the costs felt to leave financial and non-financial matters which are considered to lack alternatives; and normative commitments bind to the obligation that members feel they remain within an organization and build particular cultural expectations. According to $\mathrm{Wu}$ et al. (2004) when the presence of normative commitment among channel members will encourage firms to work together in order to achieve individual goals and with brands. Hence, normative commitment can lead to better coordination in the channel of business relations to its business, allowing all members to undergo a strong integration. Kwon and Suh (2005) suggest that "any enduring business transactions among supply chain partners require commitment by two parties in order to achieve their common supply chain goals." Commitment between partners in a relation is the key to attaining the expected outcomes for both companies, and has a direct and positive influence on performance (Vesna and Brencic 2004).

Giannakis (2007) suggests that performance is the result attained in meeting the firm's internal and external objectives since as a multidimensional concept, it has several attributes, including growth, continuity, success and competitiveness. Traditionally, variables in firm performance are linked to industrial structures (Rosli and Sidek 2013). Non-classical economic theory in the growth of a firm is a process of achieving a minimum average cost point. In other words, it is the process of profit optimization. Rosli and Sidek (2013) affirm that firms have to access, mobilize and disseminate resources before their growth. Various strategies adopted by a firm will also determine its performance. The strategy of a firm may be different to others. Essentially, performance of a firm is concentrated on strategy.

The indicators of firm performance include profitability, productivity, growth, satisfaction, market share and competitiveness. However, the financial element is not the solely indicator for a firm performance. The combination of financial and non-financial assessment is required to adjust to changes in the internal and external circumstances (Rosli and Sidek 2013). Giannakis (2007) reaffirms the four dimensions of firm performance, namely: internal processes, open systems, rational goals and human relations, in which each dimension is measured based on its respective variables.

H3 - Commitment in business relations influences the performance of SME retailers.

\section{Conceptual frameworks}

The conceptual framework explicates the effect of power asymmetry, trust and commitment to the performance of SME retailers, which shows the relationship among constructs in the present study. A model is built, consisting of three independent variables, namely power asymmetry, 
trust and commitment. Firm performance becomes the dependent variable. The conceptual model is adopted and modified from those developed by Morgan and Hunt (1994) and Ramaseshan et al. (2006). In their original model, Morgan dan Hunt (1994) developed The CommitmentTrust Theory which assigned commitment and trust as Key Mediating Variables (KMV) in relationship marketing concept. The model is part of the conceptual model of relationship marketing that is extensively used to analyze business relations between firms in a business network. In this study, we put commitment and trust as independent variables in our model. We believe that in the context of SME retailers trust and commitment could play as antecedents of business performance. Figure 1 shows conceptual model of this research.

\section{Research methods}

\subsection{Population and sample}

In the present study, the population is traditional SME retailers or traditional traders who have business relations with large suppliers. The sample is traditional SME retailers in Solo Raya residency. The consideration is the GRDP of the wholesale and retail trade sector in Solo Raya has grew on average approximately $16 \%$ and is the second fastest growing sector after the manufacturing industries. A total of 245 SME retailers in Solo, Klaten, Karanganyar, Sragen, Sukoharjo, Boyolali and Wonogiri are involved.

The sampling method used in this study is purposive sampling. Certain characteristics are set prior the data collection. The criteria of the sample are traditional SME retailer, aged at least 3-year, at least two employees, and partnership with large firm.

\subsection{Operational definition and variable measurement}

There are three antecedents and a dependent variable in this study. The antecedents in this study are: power asymmetry, commitment and trust. The dependent variable is business performance. We measured all variables in this study by using 5 point Likert Scale. Operational definitions of each variable are as follow:

1. Power is often labelled as the source of the position given from organization to its partners (Kim 2000, Ramseshan et al. 2006). It can be derived from the level of satisfaction to channel achievement and resources relative to channel members.

2. Trust is defined as the expectation that partner will project as expected and treat it fairly and intellectually (Lau and Lee, 2000).

3. Commitment refers to an exchange partner believing that an ongoing relationship with another is so important as warrant maximum efforts at maintaining

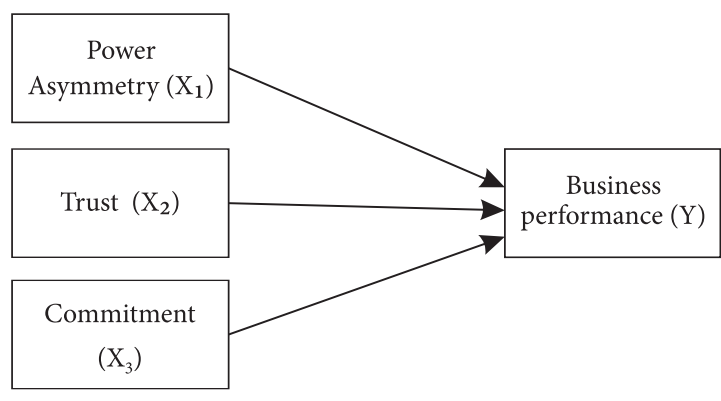

Figure 1. Research Conceptual Model (Modified from Morgan and Hunt (1994) and Ramaseshan et al. (2006))

it. It means that the committed parties believe that the relationship will be long-term (Morgan and Hunt 1994 in Chen et al. 2011).

4. Business Performance $(\mathrm{Y})$ is a description of level of fulfilled task of business's aim or target according to obtained output/conclusion at the end of a business period (Ramaseshan et al. 2006).

Table 1 shows result of validity and reliability of research instrument. In this study, validity testing of the instrument was conducted using Confirmatory Factor Analysis (CFA). The results of validity testing indicate that all items in the questionnaire have factor loading above 0.3 and grouping based on their constructs. In accordance with CFA analysis, the instrument of this study is validated to measure the constructs.

Reliability testing in this study uses Cronbach's Alpha model. Table 3 demonstrates the results of reliability testing of the constructs. Reliability testing indicates that all constructs have Cronbach's alpha coefficient of 0.6, implying the entire constructs have adequate internal consistency evidence.

\section{Data analysis and discussion}

\subsection{Characteristic of respondent}

Table 2 shows the characteristics of retailers as the respondents in the present study.

The criteria of this firm refer to Law No. 20 of 2008 concerning the criteria for micro, small and medium enterprises. Most of the respondents in the present study are retailers which are classified in the category of small and micro retailers. $48.17 \%$ of our respondents are micro retailers. They are retailers in traditional market, which has 2 employees on average. $37.55 \%$ respondents in this study are small retailer. They have 11 employees on averages. There are only $14.28 \%$ of medium retailers as respondents in this study. These retailers have 32 employees on average.

All respondents in this study are retailers in Indonesia traditional market, they sell fast moving goods that includes food and beverages. These SME retailers have certain 
Table 1. Constructs, mean, Cronbach Alpha, indicator and and factor loading of this study

\begin{tabular}{|c|c|c|c|c|c|c|c|}
\hline Construct & Mean & Cronbach & \multirow[t]{2}{*}{ Indicator } & \multicolumn{4}{|c|}{ Factor Loadings } \\
\hline $\begin{array}{l}\text { Power } \\
\text { Asymmetry }\end{array}$ & 3.6945 & 0.828 & & 1 & 2 & 3 & 4 \\
\hline & & & $\begin{array}{l}\text { Our firm has a strong influence to determine the prices of } \\
\text { our partners' products. }\end{array}$ & 0.658 & & & \\
\hline & & & $\begin{array}{l}\text { Our firm is able to provide advice to partner in order to } \\
\text { improve the product quality }\end{array}$ & 0.452 & & & \\
\hline & & & $\begin{array}{l}\text { In the case our firm fails in meeting the expectation of our } \\
\text { main partner, we will obtain poor service }\end{array}$ & 0.788 & & & \\
\hline & & & $\begin{array}{l}\text { In the case our firm rejects the advice of our main partner, } \\
\text { we will obtain a rigid warning from our partner. }\end{array}$ & 0.810 & & & \\
\hline & & & $\begin{array}{l}\text { In the case our firm does not carry out the activity expec- } \\
\text { ted by our main partner, we will experience a delay in } \\
\text { paying invoices. }\end{array}$ & 0.696 & & & \\
\hline & & & $\begin{array}{l}\text { In the case our firm follows the advice and recommen- } \\
\text { dations of our main business partner, we will gain better } \\
\text { service. }\end{array}$ & 0.547 & & & \\
\hline & & & $\begin{array}{l}\text { Our firm will obtain more profits if we complies with the } \\
\text { recommendations or expectation of our main partner }\end{array}$ & 0.439 & & & \\
\hline Trust & 4.0582 & 0.607 & & & & & \\
\hline & & & Our main business partner is trustworthy & & & & 0.722 \\
\hline & & & Our main business partner always supports our firm & & & & 0.517 \\
\hline & & & Our main business partners is reliable & & & & 0.388 \\
\hline & & & The decisions made by our partner always benefit our firm & & & & 0.784 \\
\hline Commitment & 3.7020 & 0.625 & & & & & \\
\hline & & & $\begin{array}{l}\text { Our firm continues to maintain profitable business re- } \\
\text { lation with our main business partner. }\end{array}$ & & & 0.627 & \\
\hline & & & $\begin{array}{l}\text { It is very hard for our firm to have another business par- } \\
\text { tner in addition to our main partner }\end{array}$ & & & 0.470 & \\
\hline & & & $\begin{array}{l}\text { Our firm maintains business relationships with business } \\
\text { partners whose operational costs are affordable for our } \\
\text { firm }\end{array}$ & & & 0.489 & \\
\hline & & & $\begin{array}{l}\text { Only small number of preference for our firm to establish } \\
\text { profitable business cooperation except with our main } \\
\text { business partner }\end{array}$ & & & 0.677 & \\
\hline $\begin{array}{l}\text { Business } \\
\text { Performance }\end{array}$ & 3.9945 & 0.788 & & & & & \\
\hline & & & $\begin{array}{l}\text { The level of sales of our firm has increased since our par- } \\
\text { tnership with recent main supplier }\end{array}$ & & 0.741 & & \\
\hline & & & $\begin{array}{l}\text { Our firm continues to grow since our partnership with } \\
\text { recent main supplier }\end{array}$ & & 0.732 & & \\
\hline & & & $\begin{array}{l}\text { The profit of our firm continues to increase since our } \\
\text { partnership with recent main supplier }\end{array}$ & & 0.708 & & \\
\hline & & & $\begin{array}{l}\text { The market share of our firm has continued to increase } \\
\text { since our partnership with recent main supplier }\end{array}$ & & 0.733 & & \\
\hline
\end{tabular}


Table 2. Distribution of respondents based on firm criteria

\begin{tabular}{|c|l|c|c|}
\hline No & \multicolumn{1}{|c|}{ Criteria } & N & Percentage \\
\hline 1. & Medium retailer & 35 & 14.28 \\
2. & Small retailer & 92 & 37.55 \\
3. & Micro retailer & 118 & 48.17 \\
& Total & $\mathbf{2 4 5}$ & $\mathbf{1 0 0}$ \\
\hline
\end{tabular}

competitiveness, they are loyal customers. In our survey we found that $70 \%$ of respondents have loyal customer with age of relationship more than 5 years.

\subsection{Hypothesis testing}

In this study we developed an estimation model based on Morgan and Hunt (1994) and Ramaseshan et al. (2006). Equation 1 is the estimation model of this study:

$$
\begin{gathered}
\text { Business Performance }=\alpha+\beta_{1} \text { Commitment }+ \\
\beta_{1} \text { Trust }+\beta_{3} \text { Power Asymmetry }+\varepsilon_{i} .
\end{gathered}
$$

In this study, hypotheses are tested in the multiple regression models. Table 3 shows the result of regression analysis.

Table 3 shows the result of hypotheses testing by using multiple regression. The hypothesis testing with multiple regression analysis shows $\mathrm{p}$-value is significant or greater than the level of significance of 0.05 , for the beta coefficient of the commitment construct, trust construct and power asymmetry construct. Based on the analysis, it can be claimed that the constructs of commitment, trust and power asymmetry have a significant positive effect on the performance of SME retailers. The coefficient of determination number is 0.328 , which is low goodness of fit, but it is acceptable since the aim of the present study is not the development of an estimation model, but a hypothesis testing.

\section{Discussion}

In this study, trust is a vital aspect that sustains the continuity of business relations between suppliers and SME retailers. It has the biggest beta coefficient compare to other antecedents in the model. Trust will maintain a trusting relationship between partners in various collaborations to determine strategies efficiently and effectively to achieve success in firm performance. Intensified trust leads to concern for a relationships and the emphasis in developing and maintaining further relationships to influence organizational performance and satisfaction of members (Maloni and Benton 2000). Strong relations built on the basis of trust might lead an organization to optimize synergy and respond any issues quickly to alter and solve problems between organizations so as to create a competitive advantage. Ejdys (2018) also found that trust has important role in organizations. Building trust is a process, there are several factors
Table 3. The Result of Hypothesis Testing (source: Primary data processing 2018)

\begin{tabular}{|l|c|c|c|}
\hline \multicolumn{1}{|c|}{ Variable } & Coeficient $\beta$ & $\mathrm{T}$ & Sig. \\
\hline Constant & 4.083 & & \\
\hline Commitment & 0.176 & 2.563 & 0.011 \\
\hline Trust & 0.380 & 5.256 & 0.000 \\
\hline Power Asymmetry & 0.120 & 3.512 & 0.001 \\
\hline
\end{tabular}

$\begin{array}{lll}\text { F Stat } 39.291 & \text { Sig. F } 0.000\end{array}$

$\mathrm{R}^{2}=0.328$

that could affect trust, one of them is institutional trust (Ejdys 2018). In this study, we find that traditional retailers have bigger trust to suppliers based on their institution, for example, several suppliers from national or multinational manufacturer considered trustworthy.

In this study, commitment also plays an important role in the relationship between suppliers and SME retailers. Commitment refers to an exchange partner believing that an ongoing relationship with another is so important as to warrant maximum efforts at maintaining it. It means that the involving parties must believe that the relationship will be a long term one (Kwon and Suh 2005, Rufin and Molina 2015). Suppliers and SME retailers develop and sustain stable long-term to gain mutually beneficial partnership from that commitment. It means that both parties should commit in fulfilling their obligations of keep their partners achieve excellent business performance. In this study the average periods of stable business relationship is more than 3 years. Kwon and Suh (2005) suggest that any enduring business transactions among supply chain partners require commitment by two parties in order to achieve their common supply chain goals. In a business relationship, both partners must be committed since it is the key to achieving the desired results for both companies as well as it has a direct and positive impact on performance (Rosli and Sidek 2013). In this context, commitment is categorized as continuance commitment based on the calculation of benefits obtained from a business relationship. However, in our estimation trust has bigger beta coefficient compare to commitment.

Commitment and trust in business relations are manifested in the form of agreements between suppliers and SME retailers. Such agreements are only in the form of invoice or purchase order. It is merely in the form of invoice, while the return agreement is verbal agreement. There is no written contract between suppliers and retailers that regulates technical business agreements. Meanwhile, the trust between suppliers and SME retailers usually occurs due to an emotional bond between the sales person and the retail owner (kiosk owners in traditional markets). This emotional bond often represents when retail owners invite sales person - who represents supplier from large companies - at their private ceremonies. 
In this study, power asymmetry between large companies and SME retailers is mostly depicted in the influence strategy with non-coercive power. The real form of this strategy is to provide rewards to SME retailers in order to improve their performance, for instance discount for sales with a large number of units, product returns with more specific agreements and gifts for the highest selling retail. Morgan and Hunt (1994) claim that the use of non-coercive power of reward is more effective in motivating and improving the performance of partner businesses and the supplier at the same time. Ryciuk (2017) identifies asymmetrical relationship in business relationship could reduce inter organizational trust. Asymmetrical relationship in this study has similar concept with power asymmetry. It is a result of poor bargaining position of one side in a business relationship. In this study, many micro retailers in Indonesia’s traditional market suffer poor bargaining position against their supplier from modern distributor. This condition appear in price agreement which often determined by modern distributor and the retailer should follow this policy. Modern distributor has power to determine price since they hold product supply chains and SME retailers just a small part of the chains.

Suppliers from large firms are basically more dominant and powerful than the SME retailers. Nevertheless, the estimation model in this study is inadequate to identify which party has more dominant power. Based on observations, the suppliers of large firms have the lofty power so that they are able to use the influence strategy towards SME retailers. This influence strategy is conducted to determine sale targets, minimum prices, product return and rewards for SME retailers that can meet particular standards.

Power asymmetry between suppliers of large firms and SME retailers are optimally utilized by suppliers to improve their performance. Such an improvement occurs because traditional SME retailers also experience a better business performance due to their efforts to meet the target in order to gain rewards from suppliers.

\section{Conclusions: influence strategy and construct development}

A study about the pattern of business relations between suppliers from large firms and traditional SME retailers has been conducted. It concludes several points as follows:

Power asymmetry has a positive influence on business performance. It is a source of influence strategy for firms with dominant power in a business relation. It serves as a tool for determining the quality of business relation. In the present study, large firms or suppliers use the influence strategy sourced from power to improve their business performance as well as traditional SME retailers as their partner.

Commitment has a positive influence on business performance. Commitment between suppliers from large firms and SME retailers is a business strategy is important to maintain the quality of long-term business relations. In this study, commitment is a continuance, namely commitment by taking into account the benefits of a business relationship. It is demonstrated by the focus on the long-term interests of partners in determining firm policy.

Trust in business partners has a positive influence on business performance. It is a vital basis for a long-term business relationship. In this study, trust is realized by the presence of flexible business agreements between suppliers of large firms and traditional SME retailers. It includes the absence of compelling bond in business relations between suppliers from large firms and SME retailers. It is manifested in the form of invoice/purchase order and verbal agreement, yet such relation can be a long-term business relation.

This study contributes to literature in the field of marketing or business to business marketing (B2B), particularly in the issue of business relations or business networking between firms. The present study strengthens the findings of the relationship marketing model from Morgan and Hunt (1994) about the role of power in a business relationship. The findings also show that power asymmetry has a positive influence on improving business performance of all parties involved in a business relation. Commitment and trust have an important role as an independent variable that explains the business performance of parties in a business relation. It reinforces Ramaseshan et al. (2006), who suggest the role of trust and commitment in business relations between shopping centers and vendors.

Nevertheless, the present study has a weakness. It does not employ the Maloni and Benton's concept of power (2000) which divides power into coercive power and noncoercive power. Consequently, the more effective type of power for the influence strategy is not identified. It is expected that further research will develop a research model by dividing power into coercive and non-coercive powers.

It is expected that further studies will develop an influence strategy that turns out to be significant for firms to optimize the outcomes of the business relations. The form of influence strategy can be the exploration of the source of firm power, which can be an important practical input for both large companies and SMEs involved in a business relation.

\section{Disclosure statement}

Authors of this article do not have any competing financial, professional, or personal interests from other parties.

\section{References}

Butaney G, Wortzel LH (1988) Distributor power versus manufacturer power: The customer role. Journal of Marketing 52: 52-63. https://doi.org/10.1177/002224298805200105 
Buuren NT (2017) Understanding the effects of power asymmetry on a start ups's innovation performance. IBA Bachelor Thesis, October $6^{\text {th }}$ 2017. Enchede. The Netherlands.

Ejdys J (2018) Building technology trust In ICT Application At A University. International Journal of Emerging Markets 13 (5): 980-997. https://doi.org/10.1108/IJoEM-07-2017-0234

Fullerton G (2005) The impact of brand commitment on loyalty to retail service brands. Canadian Journal of Administrative Science 22: 97-110. https://doi.org/10.1111/j.1936-4490.2005. tb00712.x

Giannakis M (2007) Performance measurement of supplier relationships. Supply Chain; An International Journal 12 (6): 400-411. https://doi.org/10.1108/13598540710826335

Gronroos, Ch (1994) From marketing mix to relationship marketing: Towards a paradigm shift in marketing. Management Decision 32 (2): 4-20. https://doi.org/10.1108/ 00251749410054774

Hingley M K (2005) Power imbalance in UK agri food supply channels: Learning to live with the supermarkets? Journal of Marketing Management 21: 63-68. https://doi. org/10.1362/0267257053166758

Kim K (2000) On interfirm power, channel climate and solidarity in industrial distributor-supplier dyads. Journal of The Academy of Marketing Science 28 (3): 388-405. https://doi. org/10.1177/0092070300283007

Kwon IWG, Suh T (2005) Trust, commitment and relationships in supply chain management; A path analysis. Supply Chain Management 10 (1): 26-33. https://doi.org/10.1108/ 13598540510578351

Lau GT, Lee SH (2000) Consumer's trust in a brand and the link to brand loyalty. Journal of Market Focused Management 4: 341-370. https://doi.org/10.1023/A:1009886520142

Maloni M, Benton WC (2000) Power influences in the supply chain. Journal of Business Logistics 21 (1): 49-73.

Morgan RM, Hunt SD (1994) The commitment-trust theory of relationship marketing. Journal of Marketing 58 (3): 20-38. https://doi.org/10.1177/002224299405800302

Porter ME (1980) Competitive strategy. New York: The Free Press.

Ramaseshan B, Leslie CY, Pae JH (2006) Power, satisfaction and relationship commitment in Chinese store-tenant relationship and their impact on performance. Journal of Retailing 82 (1): 63-70. https://doi.org/10.1016/j.jretai.2005.11.004

Ratnasingam P (2000) The influence of power on trading partner trust in electronic commerce. Internet Research: Electronic Networking Applications and Policy 10 (1): 56-62. https:// doi.org/10.1108/EUM0000000005316
Rosli MM, Sidek S (2013) The impact of innovation on the performance of small and medium manufacturing enterprise: Evidence from Malaysia. Journal of Innovation Management in Small \& Medium Enterprise 20: 16. https://doi. org/10.5171/2013.885666

Rufin R, Molina CM (2015) Moderating effects of familiarity and experience in the relationship of trust with it antecedents and consequences. E Service Journal 9 (3): 19-42. https://doi. org/10.2979/eservicej.9.3.19

Ryciuk U (2017) Identification of factors related to trust formation in construction supply chains. 7th International Conference on Engineering, Project, and Production Management. Procedia Engineering 182: 627-634. https://doi.org/10.1016/j. proeng.2017.03.168

Ryu S, Soonhong M, Nobuhide Z (2008) The moderating role of trust in manufacturer-supplier relationships. Journal of Business \& Industrial Marketing 23 (1): 48-58. https://doi. org/10.1108/08858620810841489

Sahadev S (2008) Economic satisfaction and relationship commitment in channels: The moderating role of environmental uncertainty, collaborative communication and coordination strategy. European Journal of Marketing 42 (1): 178-195. https://doi.org/10.1108/03090560810840961

Spekman RE, Carraway R (2006) Making the transition to collaborative buyer-seller relationship: An emerging framework. Industrial Marketing Management 35: 10-19. https://doi. org/10.1016/j.indmarman.2005.07.002

Srinivasan R, Moorman Ch (2005) Strategic firm commitments and rewards for customer relationship management in online retailing. Journal of Marketing 69: 193-200. https://doi. org/10.1509/jmkg.2005.69.4.193

Suvanto H (2012) Constructing a typology of trust in asymmetrical food business relations. British Food Journal 114 (7): 926-943. https://doi.org/10.1108/00070701211241536

Vesna ZM, Makovec B (2004) Values, trust, and commitment in business-to-business relations. International Marketing Review 21 (2): 202-215. https://doi.org/10.1108/02651330410531402

Viitaharju L, Merja L (2012) Antecedents of trust in asymmetrical business relations; Differing perceptions between food producers and retailers. Marketing Intelligence and Planning 30 (5): 567-587. https://doi.org/10.1108/02634501211251061

Wu W-Y, Chiag Ch-Y, Wu Y-J, Tu H-J (2004) The influencing factors of commitment and business integration on supply chain management. Industrial Management \& Data Systems 104 (4): 322-333. https://doi.org/10.1108/02635570410530739 